\title{
Knowledge and adherence to antiretroviral therapy among adult people living with HIV/AIDS treated in the health care centers of the association "Espoir Vie Togo" in Togo, West Africa
}

Yao Potchoo ${ }^{1 *}$, Kpatcha Tchamdja ${ }^{2}$, Agnon Balogou ${ }^{1}$, Vincent P Pitche ${ }^{1}$, Innocent P Guissou ${ }^{3}$, Etienne K Kassang ${ }^{4}$

\begin{abstract}
Background: The efficiency of antiretroviral therapy (ART) depends on a near perfect level of patients' adherence. The level of adherence of adults HIV-infected patients treated in the HIV/AIDS health care centres of the association "Espoir Vie Togo" in Togo, West Africa is not properly documented. The aim of the present study was to examine by means of self-reports the knowledge, the adherence level and associated factors to antiretroviral therapy (ART) among these patients.

Methods: We conducted a cross-sectional survey among adult people living with HIV/AIDS (PLWHA) through a structured questionnaire.

Results: A total of 99 patients were enrolled. Among them, 55.6\% knew the name of antiretroviral agents of regimens prescribed. All patients had a good knowledge of treatment schedule. The treatment regimens based on 2 NRTIs +1 NNRTI were used in $90 \%$ of patients. The average adherence rate was $89.8 \%$ of the total doses prescribed while $62.62 \%$ of patients showed an adherence rate of $95 \%$ or above. The treated groups were similar in term of median \% of medication doses taken according to PLWHA epidemiological characteristics. However, patients reported forgetting (34.9\%), travel (25.6\%), cost of treatment (13.9\%) and side effects (11.6\%) as the main factors of missing at least once a dose intake.

Conclusion: These results should encourage the association and all the involved actors in the HIV/AIDS's program to strengthen counseling, education and information interventions for HIV-infected patients in order to overcome the potential barriers of poor adherence.
\end{abstract}

\section{Background}

Since 1996, progress in the field of antiretroviral therapy has led to the reduction of about $80 \%$ of deaths, the number of cases of acquired immunodeficiency syndrome (AIDS) and the incidence of opportunistic infections [1]. About twenty drugs belonging to 4 classes defined according to their pharmacological modes of action constitute the current arsenal of antiretroviral drugs (ARVs). The combinations of these drugs have dramatically changed the prognosis of an infection

\footnotetext{
* Correspondence: ypotchoo@hotmail.com

'Université de Lomé, Faculté Mixte de Médecine et de Pharmacie, BP 1515, Lomé - Togo

Full list of author information is available at the end of the article
}

which natural consequence is death for over $90 \%$ of the patients into chronic infection $[2,3]$. The long-term nature of the disease has further complicated its management. In this context, sustained adherence is an essential tool of the long-term efficiency of ARVs therapy [4] (e.g. significant reduction in viral load, drug resistance, deterioration of health status and treatment failure) [5-8]. In addition, the role of the knowledge of treatment regimens [9] and cognitive demands related to the complexity of ARVs pharmacotherapy [10,11] were reported as factors that may influence the level of adherence [12,13]. Recent studies on patients' adherence in African health contexts showed that it is relatively 
higher than that of industrialized countries health context $[14,15]$.

Cohorts followed up in developed countries have emphasized the frequency of non-adherence situations, the high level of adherence required to obtain optimal efficiency of ARVs chemotherapy, and delay the beginning of the human immunodeficiency virus (HIV) resistance and pejorative evolution of the disease $[6,16]$.

The assessment of adherence, parameter that has no standard method of measurement, which varies over time, meets a number of methodological difficulties [5]. Few studies have documented the factors involved and the level of adherence of adults people living with HIV/ AIDS (PLWHA) to ARVs therapy in Togo, West Africa. The objectives of the present study were to assess the knowledge of the treatment regimens prescribed to patients; quantify the level of adherence to ARVs therapy and identify the factors related to non-adherence.

\section{Eligible patients and method}

The present study was a cross-sectional survey carried out during the months of August and October 2005 in the HIV/AIDS health care centers (in urban areas of Lomé and Sokodé) of the association "Espoir Vie Togo" (EVT), the first organized non-governmental organization of people living with HIV/AIDS and those contributing to their support. The association is recognized by National HIV/AIDS Control Programme "Programme National de Lutte contre le SIDA" (PNLS-Togo) as an ambulatory HIV/AIDS health care association. The association is also involved in the purchasing of ARVs for its members from the "Centrale d'Achat de Médicaments Essentiels et Génériques" (CAMEG-Togo). The ARVs are supplied to the patients, in EVT's pharmaceutical stores.

We interviewed eligible HIV-infected adults when they came to EVT's pharmaceutical stores to receive their monthly supply of ARVs. The enrolment was done on a voluntary basis.

\section{Inclusion criteria}

To be enrolled in the study, HIV-infected patients have to meet the following criteria: all adult patients over 15 years, the members of EVT association placed on ARVs therapy for over 1 month, who receive ARVs in EVT pharmaceutical stores. Hospitalized patients and those whose age is below 15 years were excluded from the study.

\section{Data collection method and variable of interest}

A cross-sectional survey was conducted from a structured questionnaire (additional file 1) submitted to enrolled patients (face-to-face interviews for about 30-45 $\mathrm{mn}$ ). The relevant data were collected for a period covering one month per EVT's health care centre (August and October 2005). Data collected concerned the following variables:

- The characteristics of patients (sex, age, educational level) and ARVs procurement;

- The patient treatment knowledge which was assessed through the knowledge of the names of the various drugs prescribed their respective dosages (number of tablets per dose and number of daily intakes) and the times of intake. The statements of patients were compared with the prescriptions and the treatment regimens mentioned in their health card;

-The type of ARVs combination regimens prescribed;

- The rate of adherence to treatment by means of selfreporting: It was assessed in the last month and defined as the number of doses taken during the last 7 days before each interview. Adherence score was expressed as the proportion (\%) of tablets taken compared to prescribed tablets. An adherence rate of $95 \%$ or more was considered to be good.

-The factors that induced poor adherence to treatment.

Given that the Ethic Committee was not available at the period of the study, the Ministry of the Health authorized the survey.

\section{Statistical analyses}

The median \% of medication doses taken by treated groups were compared using ANOVA method (Sigma Stat32 software; Jandal Corp, San Rafael, CA): t test was used for the sex factor; Mann-Whitney Rank sum test was used for the ARVs procurement and the ARVs combination prescribed and Kruskal-Wallis one-way analysis of variance on ranks method was used for the age groups and the educational level. The difference between the groups was considered to be significant if $\mathrm{p}<0.05$.

\section{Results}

A total of 99 patients (77.3\%) of 128 interviewed during the investigation, accepted to be submitted to the questionnaire.

\section{Sex and age of patients}

Of the total sample ( $\mathrm{n}=99), 76$ were female $(76.8 \%)$ and 23 male $(23.2 \%)$ with a sex ratio of 0.3 . The age of patients ranged between 21 to 57 years, with an average age of 36.8 years. The age group from 36 to 45 years was more representative $(39.4 \%)$, followed by 26 to 35 years $(34.3 \%)$.

\section{ARVs procurement}

Among the patients included in this study, sixty one percent were under an individual financial participation 
of "5 000 fcfa" per month (approximately US \$ 11 reduced to US \$ 2 since November 2005), the remaining received ARVs free of charge.

\section{Treatment regimen knowledge}

Forty four patients (44.4\%), knew perfectly the names of various ARVs included in the combination regimens. All respondents had a perfect knowledge of the treatment schedule (number of tablets per dose, the number of daily intakes and the times of drug intake).

\section{Types of ARVs combinations prescribed}

All patients have received a combination of three ARVs. Four different ARVs combinations (ARVs-GF (Global Fund)) were legalized, of which one available fixed-dose combination (lamivudine + stavudine + nevirapine). Only $39.4 \%$ of patients have received this fixed-dose combination as against $60.6 \%$ who were placed on nonfixed-dose combinations.

The treatment regimen containing 2 nucleoside reverse transcriptase inhibitors (NRTIs) + 1 non-nucleoside reverse transcriptase inhibitor (NNRTI) was used in $89.9 \%$ of patients; While the remaining $10.1 \%$ were placed on 2 NRTIs +1 protease inhibitor (PI) based regimens (Figure 1).

\section{Adherence rate to ARVs therapy}

The average individual adherence level was $89.8 \%$ of doses taken while sixty two (62) patients (62.62\%) reported $95 \%$ or more of the doses taken. Table 1 shows the distribution of median \% of medication doses taken according to the PLWHA epidemiological characteristics and $\mathrm{P}$ values. Except patients group who received 2 NRTIs + 1 PI combination (median percent of $46 \%$ of doses taken), the median percent of other treated groups varied from $82 \%$ to $92 \%$ of doses prescribed.

\section{Factors of non-adherence}

Forgetting (34.9\%), travel (25.6\%), cost of treatment (13.9\%) and side effects (11.6\%) were the main factors of poor adherence reported by the 43 patients who missed at least once a dose intake (Figure 2). They reported using a method in order not to forget the medication intake. Among them 69.4\% stated using a watch and/or an alarm clock to remember the time of drug intake, while $27.9 \%$ referred to parents' recall for the medication intake.

Twelve patients (12.1\%) stopped or changed one or more ARVs included in the treatment regimens because of side effects in 6 patients (6.1\%), inefficiency in 4 patients (4\%) and because of disease in 2 patients (2\%).

\section{Discussion}

The assessment of the adherence level by interviewing PLWHA seems to be an acceptable method in Africa. It is simple, cheap and accessible. This method has, however some limits (the length of interview, the subjectivity of patient statements). The fact that the investigator is unknown to the patients, that he is not a member of the health care team and the guarantee of patient's anonymity limit this bias (e.g. the patients were not afraid of being criticized for poor adherence). An additional objective method (e.g. a count of returned pills) would have helped to improve the estimation of adherence level.

The enrollment of members of the association could lead to a biased selection if the survey acceptation is related to a certain profile of patients that we didn't clarified. However, this bias was limited because the

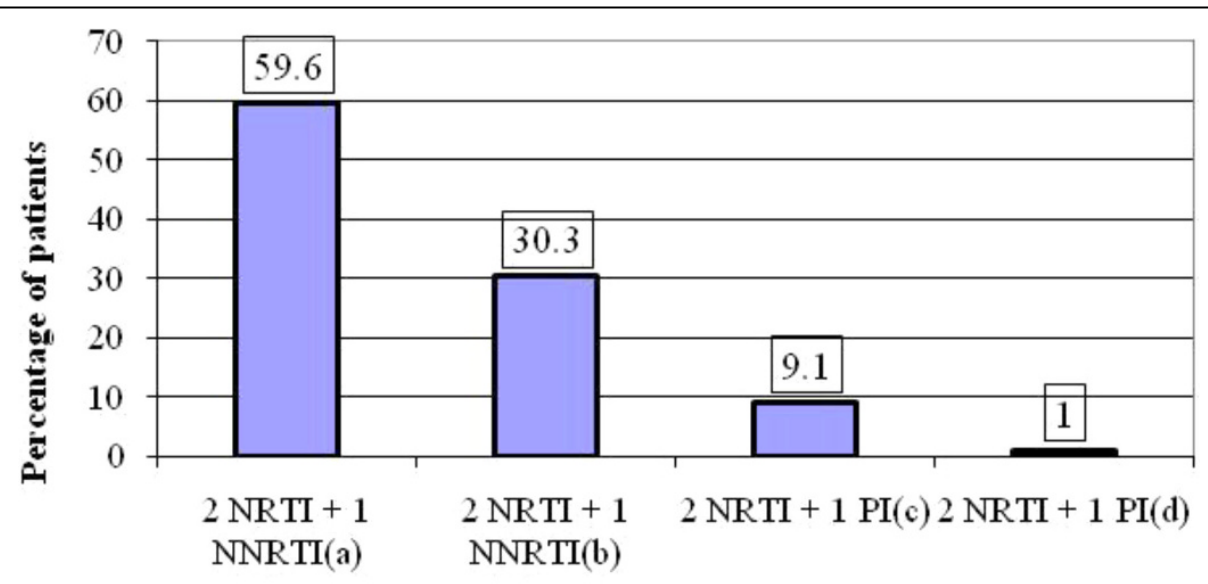

ARVs combination regimens

Figure 1 Distribution of patients according to ARVs combination regimens prescribed. (a): $3 T C+D 4 T+N V P ;(b)$ : AZT+3TC+EFV; (c): ddi+D4T +IDV; (d): ddi+D4T+NFV; AZT = zidovudine; 3TC = lamivudine; EFV = efavirenz; D4T = stavudine; NVP = nevirapine; ddi = didanosine; IDV = indinavir; NFV = nelfinavir. 
Table 1 Distribution of patients and median percent of medication doses taken according to the epidemiological characteristics

\begin{tabular}{|c|c|c|c|c|}
\hline \multicolumn{2}{|c|}{ Epidemiological characteristics } & \multirow{2}{*}{$\begin{array}{ll}n \\
28\end{array}$} & \multirow{2}{*}{$\begin{array}{c}\text { Median \% of doses taken } \\
85.00\end{array}$} & \multirow{2}{*}{$\frac{\mathbf{p}}{0.604^{\mathrm{a}}}$} \\
\hline Sex & Female & & & \\
\hline & Male & 9 & 92.00 & \\
\hline \multirow[t]{4}{*}{ Age groups } & $15-25$ years & 3 & 85.00 & $0.838^{b}$ \\
\hline & $26-35$ years & 14 & 88.50 & \\
\hline & $36-45$ years & 11 & 85.00 & \\
\hline & $>45$ years & 9 & 92.00 & \\
\hline \multirow[t]{4}{*}{ Educational level } & Non scolarised & 8 & 82.00 & $0.536^{\mathrm{b}}$ \\
\hline & Primary level & 12 & 92.00 & \\
\hline & Secondary level & 16 & 89.00 & \\
\hline & Universitary level & 1 & 85.00 & \\
\hline \multirow[t]{4}{*}{ Triple ARVs therapy received } & 2 NRTIS + 1 NNRTI & 35 & 85.00 & $0.638^{c}$ \\
\hline & 2 NRTIS + $1 \mathrm{PI}$ & 2 & 46.00 & \\
\hline & Fixed combination & 17 & 85.00 & $0.626^{c}$ \\
\hline & Non fixed combination & 20 & 87.00 & \\
\hline \multirow[t]{2}{*}{ ARVs procurement } & Offered ARVs free of charge & 16 & 85.00 & $0.269^{c}$ \\
\hline & Fixed participation of $11 \$ /$ month & 21 & 92.00 & \\
\hline
\end{tabular}

n: number of patients; a: t-test; b: Kruskal-Wallis one way ANOVA on ranks; c: Mann-Whitney Rank Sum Test

enrollment concerned consecutive patients attending EVT health care centres during the period of the study.

The sex ratio in the present study $(0.3$ with $76.8 \%$ of women) is twice as high compared to that observed by PNLS [17] and lower than that of South Africa (0.4) [18], Uganda (0.5) [19] and Senegal (1) [20] cohorts. Previous reports in Senegal [21], Morocco [22] and Benin [23] have showed the highest proportion of male. The patients' average age is similar to that of PNLS [17] but less than that reported in Senegal (38 years) [20] and higher than that observed in Kenya (31.5 years) [24], Morocco (35.5 years) [22] and in Bothswana (35.6 years) [25].

The whole eligible patients followed the regimens and the treatment schedule prescribed compared to Diabate et al's report in Ivory Cost (76.2\% of the patients followed their regimen special instructions as against $63.6 \%$ who took their medication at the prescribed time) [26]. However, only 55.6\% ( $\mathrm{n}=55)$ knew perfectly the names of ARVs prescribed. This proportion can be explained by the high proportion of illiterate patients (19.2\%). As previously reported, treatment knowledge [9] and the cognitive demands related to complexity of ARVs pharmacotherapy $[10,11]$ have been targeted as necessary components of adherence.

Standard triple-ARVs combination regimens were prescribed. Four types of ARVs combinations of which two were based on 2 NRTIs + 1 NNRTI (standard first-line regimen proposed by WHO) and two on 2 NRTIs +1 PI (Figure 1) were used compared to 16 different combinations reported by Roux et al [23] in Benin.

About $90 \%(n=89)$ of patients were in 2 NRTIs +1 NNRTI-based regimens (Figure 1). This proportion is similar to that observed by PNLS-Togo (90.8\%) after a national evaluation of ARVs therapy [17]. These regimens available in many other sub-Saharan African countries [18-20,25,26] are recommended because of their virological and immunological efficacy. They contribute to improve adherence as there is an available fixed-dose combination (lamuvidine + stavudine + nevirapine) as first-line ARVs regimen. This fixed-dose combination available in other African countries [19,26] used by $39.4 \%$ ( $n=39$ ) of patients was highly appreciated because it requires only 2 daily intakes of one tablet, promoting adherence. However, in this study, we didn't observe any statistical difference between treated groups placed on a fixed-dose combination and treated groups who received non-fixed-dose combinations.

The average adherence rate was close to that observed in Senegal (91\%) [21], but lower than that reported by Vriesendorp et al [25] in Botswana (98\%) on the basis of patients' reports. Several studies showed that $90 \%$ to $95 \%$ of medication doses should be taken for optimal virologic suppression and reduction of virologic failure 


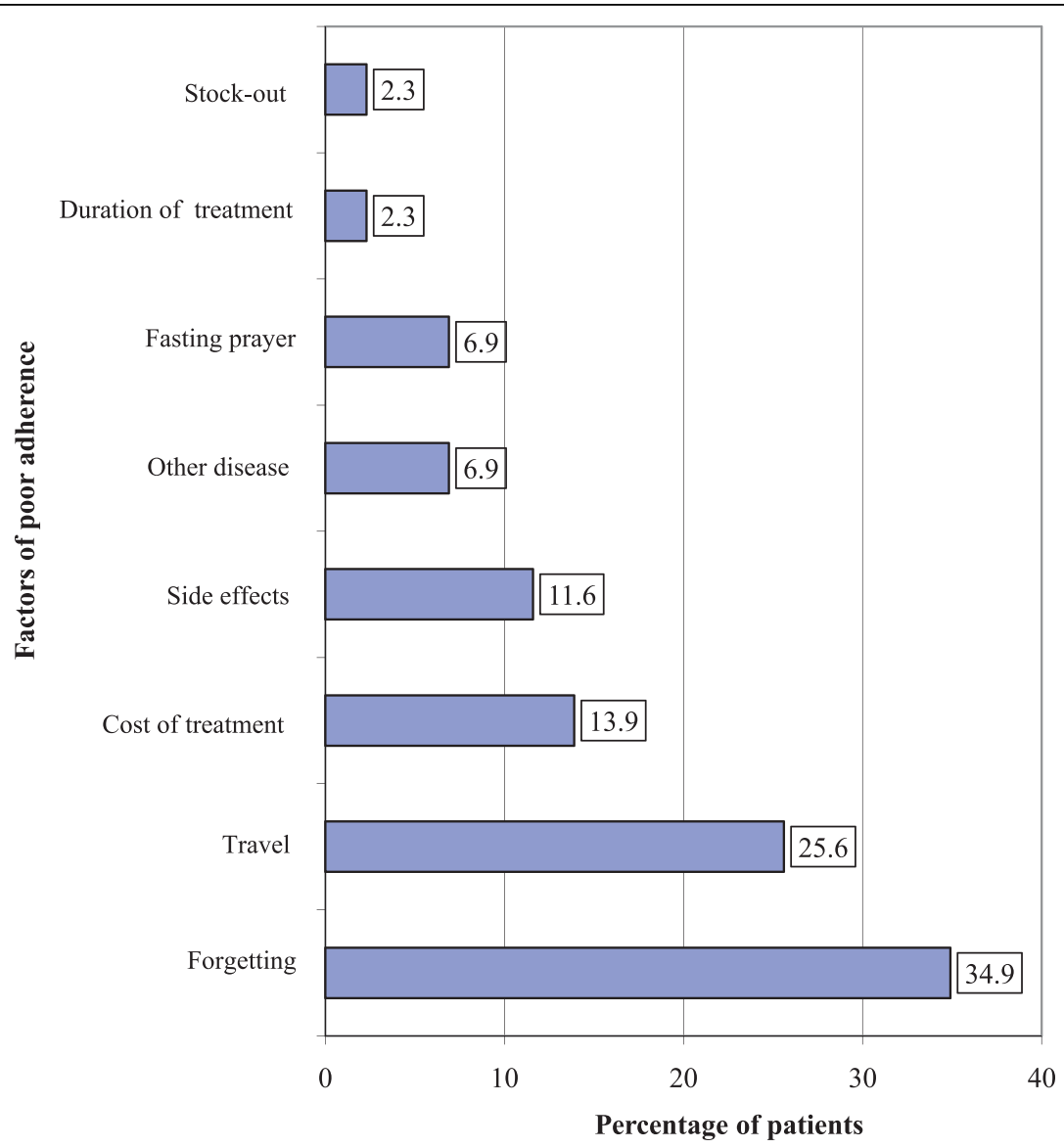

Figure 2 Distribution of patients $(n=43)$ according to the factors of poor adherence.

[27] but according to two studies, a moderate adherence (80-90\%) should lead to a better viral suppression under more potent regimen including NNRTI $[28,29]$. Otherwise, adherence rate of $95 \%$ or greater is strongly correlated with CD4 cell count increase, viral load and morbidity decreases [6]. The proportion of patients with adherence level of $95 \%$ or more $(62.62 \%)$ is less compared to previous reports in Ivory Cost (74.3\%) [26]. Adherence level could be improved if adherence data sheets updated by prescribers were available allowing patients follow-up.

Table 1 includes median \% of medication doses taken according to patients' epidemiological characteristics. No significant difference have been observed between the treated groups according to the sex, the age groups, the educational level, the ARVs regimen prescribed and the ARVs procurement ( $p>0.05$ ). Ours findings confirm those of previous studies $[19,30]$ concerning these three first factors (excluding younger age). This lack of difference among treated groups could be explained by the sensitization of the PLWHA on the role of ARVs therapy adherence by the association "Espoir Vie Togo".
The existence of tools or methods to promote the adherence was also reported. In the present study, $43.4 \%$ $(n=43)$ of patients reported using at least one $(69.4 \%$ recognized using a watch/alarm clock to remember the times of medication intake) compared to $27.9 \%$ who stated being reminded by parents.

Forgetting, travel, cost of treatment and side effects (Figure 2) have been cited by 43 patients having missed at least one dose of treatment as the main factors influencing the adherence score and often reported in similar studies $[15,19,24]$. Missing drug intake is mainly related to a state of well being feeling experienced by the patients, lack of a square meal a day (specific factor in Africa) [31-33] on which the medication intake is regulated and a feeling of weariness suitable for all longterm treatment. There is therefore the need to strengthen advice and information on the consequences of poor adherence for the patient himself and the threat for the public health when he does not take his medications.

Travels were the second main factor of poor adherence. This factor of non-adherence reveals the problem of the lack of a pill container containing at least all daily doses. 
The cost of treatment comprising transport, food support and laboratory tests were cited as main obstacles to optimal adherence. Previous studies have reported the incidence of payment factor on the rate of loss in HIVinfected patients' follow-up and/or adherence in Kenya [24]. The risk of reduction in terms of loss to follow-up related to offering ARVs free of charge was $56.6 \%$ in cohorts study [24].

Side effects were the 4th barrier of non adherence (11.6\%). They were collected on the basis of patients' reports. As a result, we have not considered appropriate to mention them since they are not validated as such in contrast to the report of Bhengu et al [34] who conducted a study on the prevalence of symptoms reported by patients. They have been also reported (including their severity) as main factors for poor adherence in previous studies $[9,25,35,36]$. On the contrary, Bhengu et al [34] observed no significant relationships between adherence and the intensity of symptoms. Of the 99 patients included in this study, 89 patients (89.9\%) reported side effects due to ARVs treatment received. This proportion is higher than that reported in a national survey by PNLS (31.6\% of PLWHA) [17]. In the present study, five patients $(11.6 \%, \mathrm{n}=43)$ failed to take their medication because of side effects. The influence of these side effects may be lessened by a good patient information and training to enable them to handle themselves some minor side effects.

A total of 12 patients (12.1\%) stopped or changed one or more ARVs of the combination regimen for side effects, inefficiency of treatment and for illness conditions compared to $49.9 \%$ reported in the national survey conducted by PNLS [17].

Overall, a review of the literature shows that the ARTadherence determinants include institutional, socio-economical, psychological and therapeutic factors to take in account in the management of PLWHA care. However, the present study didn't observe any epidemiological characteristic associated with poor adherence (medication doses taken less than 95\%). To reach optimal adherence level (100\%), our findings suggest the improvement of PLWHA follow-up with the help of adherence data sheets, the counseling/information/education interventions concerning the virological, biological, therapeutic and public health risks of nonadherence to ARVs therapy.

\section{Conclusion}

Our results have shown that the knowledge and the capacity for adherence to ARVs treatment of PLWHA in the present study are satisfactory but have not reached the optimum desirable level. However, these results reflect the quality of the association "Espoir Vie Togo" interventions toward PLWHA. They should encourage the association EVT and all actors involved in the fight against AIDS to maintain and strengthen counseling, education, training and information interventions for PLWHA with a view to overcoming the potential barriers of poor adherence, given that nonadherence leading to the development of ARVs-resistant HIV is a public health concern.

\section{Additional material}

Additional file 1: Questionnaire for assessing PLWHA's knowledge and adherence level to antiretroviral therapy. The questionnaire sought the epidemiological characteristics of PLWHA, their knowledge of ARVs treatment, their adherence level to ART, the factors of poor adherence, the side effects reported and the prescription of treatment.

\section{Abbreviations}

AIDS: Acquired Immune Deficiency Syndrome; ART: Antiretroviral Therapy; ARVs: Antiretrovirals; ARVs-GF: Antiretrovirals supported by Global Fund; CAMEG-Togo: Centrale d'Achat de Médicaments Essentiels et Génériques; EVT: Espoir Vie Togo (Association); HIV/AIDS: Human Immunodeficiency Virus/Acquired Immune Deficiency Syndrome; HIV: Human Immunodeficiency Virus; NNRTIs: Non-Nucleoside Reverse Transcriptase Inhibitors; NRTIs: Nucleoside Reverse Transcriptase Inhibitors; PI: Protease Inhibitor; PLWHA: People Living with HIV/AIDS; PNLS-Togo: Programme National de Lutte contre le SIDA; WHO: Word Health Organization.

\section{Acknowledgements}

The authors would like to thank: HIV/AIDS Health Care Centres of the association "Espoir Vie Togo" of Lomé and Sokodé for accepting the survey and the use of their facilities. M. Didier K. AMEGAH-WOVOE, Translator/ Interpreter for the improvement of the English language

\section{Author details}

'Université de Lomé, Faculté Mixte de Médecine et de Pharmacie, BP 1515, Lomé - Togo. ${ }^{2}$ Centre Hospitalier Universitaire de Kara, Service de Pharmacie BP 18 - Kara - Togo. ${ }^{3}$ Université de Ouagadougou - UFR/SDS 03 BP 7021 Ouagadougou 03 - Burkina Faso. ${ }^{4}$ Espoir Vie Togo, Région Centrale (EVT/RC) - Togo.

\section{Authors' contributions}

YP conceived, designed and coordinated the study, he carried out statistical analysis and drafted the manuscript; $K T$ participated in the design of the study and the questionnaire, he carried out the study (interviewing and data collection), used the data collected for sustaining a doctor thesis of pharmacy; $A B, V P P$ and IPG contributed by means of their respective competence and their experiences to the manuscript reviewing critically for its intellectual content. All authors read and approved de final version of the manuscript; EKK facilitated the interview and offered some facilities to the interviewer.

All authors read and approved the final manuscript.

\section{Competing interests}

The authors declare that they have no financial or no non-financial competing interests in relation to the present manuscript.

Received: 25 September 2009 Accepted: 17 September 2010 Published: 17 September 2010

\section{References}

1. Katlama C, Pialoux G, Girard PM: Traitements antirétroviraux. In VIH. Edited by: Girard PM, Katlama C, Pialoux G. Paris: Doin; 2004:299-329.

2. Fonquerine $L$, Girard PM: Classification, définitions et facteurs prévisionnels d'évolution de l'infection $\mathrm{VIH}-1$ chez l'adulte. In $\mathrm{VIH}$. Edited by: Girard PM, Katlama C, Pialoux G. Paris: Doin; 2004:53-63. 
3. McDonnell Holstatd MK, Pace JC, De AK, Ura DR: Factors associated with adherence to antiretroviral therapy. Journal of the Association of Nurses in AIDS Care 2006, 17(2):4-15.

4. Spire B: Problèmes cliniques et comportementaux liés à la chronicisation de la maladie. Le SIDA 20 ans après: d'une maladie mortelle à une maladie chronique. Actualité et Dossier de Santé Publique 2002, 09:23-25.

5. Chesney MA, Morin M, Sherr L: Adherence to HIV combination therapy. Social Science \& Medicine 2000, 50:1599-1605.

6. Paterson DL, Swindells S, Mohr J, Brester M, Vergis EN, Squier C Wagener MM, Smith N: Adherence to protease inhibitor therapy and outcomes in patients with HIV infection. Annals of Internal Medicine 2000, 133(Suppl 1):21-30.

7. Paterson DL, Potoski B, Capitano B: Measurement of adherence to antiretroviral medications. Journal of Acquired Immune Deficiency Syndrome 2002, 31(Suppl 2):S103-S106.

8. Fisher JD, Fisher WA, Amico KR, Harman JJ: An information-motivation behavioral skills model of adherence to antiretroviral therapy. Health Psychology 2006, 25(4):462-473

9. Jones DL, McPherson-Baker S, Lydston D, Camille J, Brondolo E, Tobin JN, Weiss SM: Efficacy of a Group Medication Adherence Intervention Among HIV Positive Women: The SMART/EST Women's Project. AIDS Behav 2007, 11:79-86.

10. Stone VE, Hogan JW, Schuman P, Rompalo AM, Howard AA, Korkontzelou C, Smith DK: Antiretroviral regimen complexity, selfreported adherence, and HIV patient's understanding of their regimens: Survey of women in the HER study. Journal of Acquired Immune Deficiency Syndrome 2001, 28(Suppl 2):124-131.

11. Remien RH, Hirky AE, Johnson MO, Weinhardt LS, Whittier D, Minh Le G: Adherence to medication treatment: A qualitative study of facilitators and barriers among a diverse sample of HIV+ men and women in four U.S. cities. AIDS and Behavior 2003, 7(suppl 1):61-72.

12. Simoni JM, Frick PA, Lockhart D, Liebovitz D: Mediators of social support and antiretroviral adherence among an indigent population in New York city. Aids Patient Care and STDs 2002, 16(Suppl 9):431-439.

13. Goujard C, Bernard N, Sohier N, Peyramond D, Lancon F, Chwalow J, Arnould B, Delfraissy J-F: Impact of a patient education program on adherence to HIV medication: A randomized clinical trial. Journal of Acquired Immune Deficiency Syndrome 2003, 34(Suppl 2):191-194.

14. Watt MH, Maman S, Earp JA, Eng E, Setel PW, Golin CE, Jacobson M: "It's all the time my mind": Facilitators of adherence to antiretroviral therapy in a Tanzanian setting. Social Science \& Medicine 2009, 68(10):1793-1800.

15. Hardon AP, Akurut D, Comoro C, Ekezie C, Irunde HF, Gerrits T, Kglatwane J, Kinsman J, Kwasa R, Maridadi J, Moroka TM, Moyo S, Nakiyemba A, Nsimba S, Ogeyi R, Oyabba T, Temu F, Laing R: Hunger, waiting time and transport costs: Time to confront challenges to ART adherence in Africa. AIDS care-psychological and socio-medical aspects of AIDS/HIV 2007, 19(5):658-665.

16. Bangsberg DR, Perry S, Charlebois ED, Clark RA, Robertson M, Zolopa AR, Moss A: Adherence to HAART predicts progressing to Aids. AIDS 2001 15(9):1181-1183.

17. Programme National de Lutte contre le SIDA (PNLS-Togo): Evaluation de la prise en charge thérapeutique des personnes vivant avec le VIH (PVVIH) par les antirétroviraux (ARV) au Togo. 2005, 1-24.

18. Coetzee D, Boulle A, Hildebrand K, Asselman V Van Cutsem G, Goemaere E Promoting adherence to antiretroviral therapy: the experience from a primary care setting in Khayelitsha, South Africa. AIDS 2004, 18(suppl 3): S27-S31

19. Oyugi JH, Byakika-Tusiime J, Ragland K, Laeyendecker O, Mugerwa R, Kityo C, Mugyenyi P, Quinn TC, Bangsberg DR: Treatment interruptions predict resistance in HIV-positive individuals purchasing fixed-dose combination antiretroviral therapy in Kampala, Uganda. AIDS 2007, 21(8):965-971.

20. Etard J-F, Lanièce I, Fall MBK, Cilote V, Blazejewski L, Diop K, Desclaux A Ecochard R, Ndoye I, Delaporte E, ANRS 1215/1290 Study Group: A 84month follow up of adherence to HAART in a cohort of adult Senegalese patients. Tropical Medicine and International Health 2007, 12(10):1191-1198.

21. Laniece I, Desclaux A, Ciss M, Diop K, Ndiaye B: L'observance des traitements antirétroviraux et ses déterminants. Analyse quantitative. In L'initiative sénégalaise d'accès aux médicaments antirétroviraux. Edited by: Desclaux A, Laniece I, Ndoye I. Paris ANRS; 2002:97-108.
22. Benjaber K, Rey JL, Himmich H: Etude sur l'observance du traitement antirétroviral à Casablanca. Médecine et maladies infectieuses 2005, 35:390-395.

23. Roux P, Rey JL, Sehonou J, Certain A: L'observance à un mois des patients sida inclus dans l'initiative béninoise d'accès aux antirétroviraux. Bull Soc Pharm Bordeaux 2004, 143:19-30.

24. Zachariah R, Van Engelgem I, Massaquoi M, Kocholla L, Manzi M, Suleh A, Phillips M, Borgdorff M: Payment for antiretroviral drugs is associated with a higher rate of patients lost to follow-up than those offered freeof-charge therapy in Nairobi, Kenya. Transactions of the Royal Society of Tropical Medicine and Hygiene 2008, 102:288-293.

25. Vriesendorp R, Cohen A, Kristanto P, Vriejens B, Rakesh P, Anand B, Iwebor HU, Stiekema J: Adherence to HAART therapy measured by electronic monitoring in newly diagnosed HIV patients in Botswana. Eur J Clin Pharmacol 2007, 63:1115-1121.

26. Diabate $\mathrm{S}$, Alery $\mathrm{M}$, Koffi CK: Determinants of adherence to highly active antiretroviral therapy among HIV-1-infected patients in Côte d'Ivoire. AIDS 2007, 21(13):1799-1803.

27. Sethi AK, Celantano DD, Gange SF, Moore RD, Gallant JE: Association between adherence to antiretroviral therapy and human immunodeficiency virus drug resistance. Clin Infect Dis 2003, 37:1112-1118.

28. Maggiolo F, Ravasio L, Ripamonti D, Gregis G, Quinzan G, Arici C, Airoldi M, Suter F: Similar adherence rates favor different virologic outcomes for patients treated with nonnucleoside analogues or protease inhibitors. Clin Infect Dis 2005, 40:158-163.

29. Bangsberg DR: Less than $95 \%$ adherence to nucleoside reversetranscriptase inhibitors therapy can lead to viral suppression. Clin Infect Dis 2006, 43:939-941.

30. Fogarty L, Roter D, Larson S, Burke J, Gillespie J, Levy R: Patient adherence to HIV medication regimens: a review of published and abstracts reports. Patient Education and Counselling 2001, 46(2):93-108.

31. Laniece I, Ciss M, Desclaux A, Diop K, Mbodj F, Ndiaye B, Sylla O, Delaporte E, Ndoye I: Adherence to HAART and its principal determinants in a cohort of Senegalese adults. AIDS 2003, 17(suppl 3):S103-S108.

32. Weiser S, Wolfe W, Bangsberg D, Thior I, Gilberg P, Makhema J, Kebaabetswe P, Dickenson D, Mompati K, Essex M, Marlink R: Barriers to antiretroviral adherence for patients living with HIV infection and AIDS in Botswana. J Acquir Immune Defic Syndr 2003, 34(3):281-288.

33. Au JT, Kayitenkore K, Shutes E, Karita E, Peters PJ, Tichacek A, Allen SA Access to adequate nutrition is a major potential obstacle to antiretroviral adherence among HIV-infected individuals in Rwanda [Letter]. AIDS 2006, 20(16):2116-2118.

34. Bhengu BR, Ncama BP, Mclnerney PA, Wantland DJ, Nicholas PK, Corless IB, McGibbon CA, Davis SM, Nicholas TP, Ros AV: Symptoms experienced by HIV-infected individuals on antiretroviral therapy in Kwazulu-Natal, South Africa. Applied Nursing Research, Correct Proof 2009.

35. McDonnell Holstatd MK, Pace JC, De AK, Ura DR: Factors associated with adherence to antiretroviral therapy. Journal of the Association of Nurses in AIDS Care 2006, 17(2):4-15.

36. Salmon-Ceron D, Deleuze J, Coste J, Guerin C, Guinburg C, Blanche P, Finkielsztejn L, Pecqueux L, Chaput S, Gorin I, Sicard D: Enquête sur l'observance des traitements antirétroviraux comportant un inhibiteur de protéase chez des patients infectés par le VIH. Paris, Masson 2000, 297-302.

\section{Pre-publication history}

The pre-publication history for this paper can be accessed here: http.//www biomedcentral.com/1472-6904/10/11/prepub

\section{doi:10.1186/1472-6904-10-11}

Cite this article as: Potchoo et al:: Knowledge and adherence to antiretroviral therapy among adult people living with HIV/AIDS treated in the health care centers of the association "Espoir Vie Togo" in Togo, West Africa. BMC Clinical Pharmacology 2010 10:11. 